\title{
Eğitimde "Looping” Tekniğinin Öğrencilere Etkisi Üzerine Bir İnceleme
}

\author{
İrem Girgin
}

Milli Ĕ̆itim Bakanlı̆̆ı, Van, Türkiye

Sorumlu Yazar: İrem Girgin, iremgrgn.0@gmail.com

Makale Türü: Derleme

Kaynak Gösterimi: Girgin, İ. (2021). Eğitimde “Looping” tekniğinin öğrencilere etkisi üzerine bir inceleme. Ĕ̌itimde Kuram ve Uygulama, 17(1), 54-66. doi: 10.17244/eku.911410

Etik Not: Araştırma ve yayın etiğine uyulmuştur. Bu çalışma, "Sistematik Derleme Makalesi” olup ayrıca bir etik onay süreci işletilmemiştir.

\section{The Effect of Looping Technique on the Students \\ İrem Girgin \\ Ministry of National Education, Van, Turkey}

Corresponding Author: İrem Girgin, iremgrgn.0@gmail.com

Article Type: Review Article

To Cite This Article: Girgin, İ. (2021). Eğitimde "Looping” Tekniğinin öğrencilere etkisi üzerine bir inceleme. Ĕgitimde Kuram ve Uygulama, 17(1), 54-66. doi: 10.17244/eku.911410

Ethical Note: Research and publication ethics were followed. This study is "Systematic Review Article"; hence, no proceed an ethical clearance evaluation. 


\title{
Eğitimde "Looping” Tekniğinin Öğrencilere Etkisi Üzerine Bir İnceleme
}

\author{
İrem Girgin \\ Milli Ĕgitim Bakanlı̆̆ı, Van Türkiye \\ ORCID: https://orcid.org/0000-0002-5361-9945
}

\begin{tabular}{|c|c|}
\hline$\ddot{\mathbf{O z} z}$ & Makale Bilgisi \\
\hline $\begin{array}{l}\text { Looping tekniği, bir eğitimcinin aynı sınıf ile birkaç sene boyunca çalışmasını ifade eden } \\
\text { bir öğretim yöntemidir. Öğrencilerde okula aidiyet, sosyalleşme becerilerinde gelişme ve } \\
\text { akademik becerilerin gelişmesi gibi alanlarda fayda sağladığı ifade edilen Looping } \\
\text { eğitimi, uzun yıllardır kullanılmakta olan bir teknik olarak literatürde belirtilmiştir. Bu } \\
\text { derleme çalışmasının amacı, Looping yönteminin öğrenciler üzerine etkisini incelemiş } \\
\text { olan araştırmaların bir araya getirilmesi olarak belirlenmiştir. Makalelerin bir araya } \\
\text { getirilmesi için sistematik derleme yöntemi kullanılmıştır. Sistematik derleme, literatüre } \\
\text { ilişkin çalışmaların seçilip eleştirel olarak değerlendirilmesi, bu çalışmalardan veri } \\
\text { toplanması ve analiz edilmesini ifade eden bir araştırma yöntemi olarak tanımlanmıştır. } \\
\text { Derleme kapsamında belirlenen anahtar kelimeler ProQuest, Google Scholar, ERIC ve } \\
\text { Semantic Scholar veri tabanlarında taranmış, 2000-2020 yılları arasında yayınlanan } \\
\text { makaleler kabul edilmiştir. Derleme sürecinde belirlenen kriterlere uygun olarak 16 adet } \\
\text { çalışma incelenmesine karar verilmiştir. İncelenen araştırmalar (a)yayınlanma yılları, (b) } \\
\text { kullanılan ölçme metodolojisi, (c) kullanılan ölçme araçları ve (d) çalışmaların } \\
\text { yürütüldüğü okul kademesi (e)çalışmanın yürütüldüğü ülke ve (f) çalışmanın türü olmak } \\
\text { üzere altı temel alanda incelenmiştir. Çalışma sonucunda en sık tercih edilmiş olan ölçme } \\
\text { metodolojisinin nicel desen, en fazla kullanılan ölçme aracının başarı testleri olduğu } \\
\text { ortaya çıkmıştır. Literatürdeki çalışmalar yayınlanma yıllarına göre ele alındığında } 2007 \\
\text { ve } 2009 \text { yıllarında yapılmış olan çalışmaların ağırlıkta olduğu bulunmuştur. Derlenen } \\
\text { çalışmalar türleri bakımından sınıflandırıldıklarında, alana ilişkin tez çalışmalarının } \\
\text { ağırlıkta olduğu bulunmuştur. İlgili konuda çalışma yapan ülkeler Amerika Birleşik } \\
\text { Devletleri (ABD) ve Çin Halk Cumhuriyeti olduğu görülmüştür, en çok çalışma yapan } \\
\text { ülke ABD olarak belirlenmiştir. Ayrıca ilişkili alanyazında en çok çalışmanın 2,3,4 ve } \\
\text { 5.sınıf ve 8.sınıf öğrencileriyle yapılmış olduğu belirlenmiştir. Looping tekniğinin, } \\
\text { öğrencilere sosval bilissel ve akademik alanlarda bircok vararı olduğu ortava çkmıstır. }\end{array}$ & $\begin{array}{l}\text { Anahtar kelimeler: Looping, } \\
\text { Looping eğitimi, Looping } \\
\text { tekniği } \\
\text { Makale Geçmişi: } \\
\text { Geliş: } 07 \text { Nisan 2021 } \\
\text { Düzeltme: } 08 \text { Haziran } 2021 \\
\text { Kabul: } 10 \text { Haziran } 2021\end{array}$ \\
\hline
\end{tabular}




\section{The Effect of Looping Technique on the Students}

\begin{tabular}{|c|c|}
\hline Abstract & Article Info \\
\hline $\begin{array}{l}\text { Looping technique is a teaching method that refers to an educator working with the same } \\
\text { class for several years. Looping technique has been many years due to its' benefits on } \\
\text { sense of belonging, development of social and academical skills. The aim of this review } \\
\text { study is to evaluate and analyze the studies that examined the effect of the looping method } \\
\text { on the students. For this purpose, systematic review method was used to gather articles. } \\
\text { The keywords determined within the scope of the study were scanned in ProQuest, } \\
\text { Google scholar, ERIC and Semantic Scholar databases, and articles published between } \\
2000-2020 \text { were accepted to the study. As a result of the scanning process a total of } 16 \\
\text { studies were reviewed. Within the scope of this study, studies on the effect of looping } \\
\text { technique on the students were examined in six main areas: (a) the years of publication, } \\
\text { (b) the methodology (c) research instruments, (d) grade levels of the studies (e) the } \\
\text { countries of studies conducted, and (f) types of the studies. As a result of the study, it was } \\
\text { revealed that the most preferred measurement methodology was the quantitative design, } \\
\text { and the most used measurement tool was revealed to be tests. Also, it is found that the } \\
\text { studies related to the literature were mainly conducted in years } 2007 \text { and } 2009 \text {. It has also } \\
\text { been revealed that studies related to the literature mainly consists of theses. To add more, } \\
\text { studies related to the topic were mainly conducted in United States of America (USA) and } \\
\text { China, while the highest number of studies were revealed to be conducted in USA. Studies } \\
\text { conducted with 2,3,4, 5th and 8th grade students were found to be predominate. In } \\
\text { addition to these results, literature review of these studies revealed that the looping } \\
\text { technique has many benefits for students especially in social, cognitive and academic } \\
\text { areas. }\end{array}$ & $\begin{array}{l}\text { Article History: } \\
\text { Received: } 7 \text { April } 2021 \\
\text { Revised: } 8 \text { June } 2021 \\
\text { Accepted: } 10 \text { June } 2021\end{array}$ \\
\hline
\end{tabular}




\section{Extended Summary}

\section{Introduction}

Looping technique refers to the teacher working with the class for a period of two or three years. While integrating the looping technique in educational settings, forming classes of students with same age is stated as an important criterion. This is explained as a result of the looping technique, that long-lasting bonds were formed between teacher, student, and parent groups. Looping education enables teachers and students to get to know each other for a long time, therefore, the teacher who spends a long time with his/her students both makes the students feel supported and the educator develops familiarity with the learning style of the individuals. On the other hand, it was revealed that looping education supported students in academical, social and emotional development areas. According to a study, it has been stated that since the same group of students study with the same classmates and teachers for two or three years, looping education supported students' long-term learning skills. Also, in another study it was revealed that looping education helped teachers to establish close relationships with students and parents. Considering the important role of looping education in the educational context, it is useful both for students' and teachers' development. As a result of the literature review, it was revealed that there were not enough studies on the effect of looping education on students in national sources. This study aims to evaluate and analyze the studies related to the literature and cover this deficiency in the national literature. Research question was determined as "What is the effect of looping education on students?"

\section{Method}

To examine articles related to literature, systematic review method was used. Systematic reviews consist of a detailed plan and a research process, that is planned with a certain search strategy by eliminating the irrelevant studies and synthesizing the relevant ones. Within the scope of the study, international studies published between years 2000-2021 were used. Theses, including articles published in refereed journals, were also used in the study. Of the scanned articles, the ones which were not research articles were not included in this study. The keywords "Looping" and "looping education" were scanned on Semantic Scholar, ERIC, ProQuest and Google Scholar databases. As a result of the scanning process, the studies unrelated to the literature and the studies unsuitable to the aim of this study were eliminated therefore 16 studies were examined in this systematic review study. Chosen studies were examined in six main areas: year of publication, methodology, research instruments, grades and classes, countries, and type of the study.

\section{Results}

According to the studies reviewed, it was revealed that the most preferred measurement methodology was the quantitative design, and the most used measurement tool was revealed to be tests. Also, it is found that the studies related to the literature were mainly conducted in years 2007 and 2009. It has also been revealed that studies related to the literature mainly consists of theses. To add more, studies related to the topic were mainly conducted in United States of America (USA) and China, while the highest number of studies were revealed to be conducted in USA. Studies conducted with 2, 3, 4, 5th and 8th grade students were found to be predominate. In addition to these results, literature review of these studies revealed that the looping technique has many benefits for students especially in social, cognitive, and academic areas.

\section{Discussion and Conclusion}

As a result of the literature review, looping technique is a method that has been used in many countries due to the advantages and benefits of it. Looping technique in educational context found to be efficient and useful in social, emotional and academical developmental areas of students. On the other hand, it was revealed that looping education also helped teacher-student, teacher-parent, and student-student relationships in a good way. To add more, it was found that looping education helped students feel a sense of belonging to the school. Considering all the benefits of the looping education it is implied that use of looping in the educational framework is suggested. The lack of articles in the literature was also noted for the future studies. It was also found the lack of studies related to the literature signals there is a need for research in this area. Given the importance of this beneficial educational technique it is important to plan future studies related to this context. In this review study only Google Scholar, Semantic Scholar, ProQuest and ERIC databases were used, And the research studies between the years 2000-2020 were examined. For further research studies this might be important to use different databases with different time periods. 


\section{Giriş}

Looping tekniği, öğretmenin eğitim verdiği sınıfla birlikte iki veya üç senelik bir döngü boyunca çalışmasını ifade etmektedir (Grant, Johnson ve Richardson, 1996; Gaustad, 1998). Looping eğitimi, öğretmen ve öğrencilerin birbirlerini uzun bir süre boyunca tanımasını sağlamaktadır. Öğrencileriyle uzun zaman geçiren öğretmenin, hem öğrencilerin desteklenmiş hissetmesini sağlamakta olduğu hem de eğitimcinin bireylerin öğrenme tarzına aşinalık geliştirdiği, ifade edilmiştir (Grant, Johnson ve Richardson, 1996). Looping eğitimi öğrencileri sadece akademik anlamda değil, aynı zamanda sosyal ve duygusal anlamda da desteklemekle ilişkili olarak belirtilmiştir (Little ve Little, 2001).

Aynı zamanda çok yıllık eğitim olarak da adlandırılan Looping tekniği uzun süredir kullanılmakta olan bir sinıf düzenleme yöntemidir (Grant ve Johnson, 1996). Looping eğitiminin kökenleri, tek derslikli evlerin okul olarak kullanılmasıyla başlanmış ardından resmi olarak ilk 1913 yılında Amerika Birleşik Devletleri (ABD) Eğitim Bakanlığı tarafindan öğretmen rotasyonu adı altında tanımlanmış ve uygulanmıştır (Grant, Johnson, Richardson ve Fredenburg, 1996). Eğitimde Looping çalışmaları, Avrupada Deborah Meier okullarında, Özel Waldorf okullarında ve Özel Reggio Emilia okullarında uygulanılmaya başlanmış, ardından Almanya ve Japonya'da uygulamalar yapılmaya başlanmışıtır (Simel,1998).

Avusturyalı bir bilim insanı olan Steiner, Waldorf okullarını fabrika çalışanlarının çocuklarına eğitim vermek için kurmuş, ardından eğitimdeki inovasyonları uygulama kabiliyeti ve başarısı sonucunda dünya çapında tanınan bir marka haline gelmiştir. 1919 yılında Waldorf okullarında Looping tekniğinin uygulanması başlanmıştır. Bu okullarda eğitimin odak noktası, öğrenmeyi teşvik etmek için öğretmen ve öğrenci ilişkisini geliştirmek olarak belirlenmiştir (Lenart,2000).

Danimarka, Looping eğitimini kendi öğretim sistemine entegre etmiş bir diğer ülke olarak literatürde belirtilmiştir. Öğrenciler, birinci sınıftan itibaren birkaç yıl boyunca aynı öğrenci grubuyla eğitim görmektedirler (Mecham, 2010). Amerika Birleşik Devletleri’nin stratejisinden farklı olarak, Danimarka'daki öğrencilerin sınıf öğretmenlerine ek olarak yardımcı olan ikinci veya üçüncü öğretmenler de görev yapmaktadır (Morrill, 2003).

Çin hükümeti, Looping stratejisini kendi eğitim sistemlerine uyarlayan bir diğer ülkedir. Bu kapsamda, öğrenciler ilkokula başladıklarında birinci sınıftan altıncı sınıfa kadar, ortaokulda da yedinci sınıftan dokuzuncu sınıfa kadar aynı sınıf grubu ve onuncu sınıftan onikinci sınıfa kadar da aynı sınıf grubuyla eğitim görecekleri biçimde ayrılmışlardır (Hitz, Somers ve Jenlink, 2007). Çin, öğrencilerin bu şekilde gruplandırılmasının, aynı gruptaki öğrencilerin devamlı öğrenmesini destekleyici, bir kademeden diğerine geçişi kolaylaştırıcı nitelikte olduğunu ifade etmiştir (Liu, 1997).

Küba, Looping eğitimi birinci sınıftan başlanarak dördüncü sınıfa kadar eğitim periyotlarıyla sürdürülmüştür. Küba Eğitim Bakanlığı sonradan bu periyodu artırarak Looping eğitimini birinci sınıftan altıncı sınıfa kadar uzatmıştır (Bolaños, 2012). Bu şekilde, ilkokuldan ortaokula geçişte yaşanabilecek öğretmen değişiklikleri ve muhtemel bağ kurma problemleri ortadan kaldırılarak, diğer kademeye geçişi öğrenciler için daha kolay bir hale getirmişlerdir (Johnston,2003).

Japonya Eğitim Bakanlığı da Looping eğitimi felsefesi benimsenmiş ve kendi anlayışına göre yorumlamıştır (Roberts, 2001). Öğretimin devamlılığının sağlanması için öğrenciler sınıf öğretmenleriyle iki yıl süreli döngüler içinde eğitimler görmüştür (Sato, 1993). Bu şekilde, öğrencilerin ve öğretmenlerin, öğretim imkanlarından maksimum düzeyde yararlanabilmeleri ve grup uyumu yoluyla bireysel ilerlemeyi en üst düzeye çıkarabilmeleri hedeflenmiştir (LeTendre, 2000.)

Almanya'da da Looping uygulaması eğitim sistemlerine adapte edilmiş, Koln-Holweide okullarında yaklaşık 100 öğrenci altışarlı gruplara ayrılarak aynı öğretmenlerle altı yıllık döngü boyunca eğitim görmüsstür (Roberts, 2001). Belirlenen altı grup içerisinde de işbirlikli öğrenmeyi desteklemek amaciyla daha en az dört kişilik küçük gruplar kurulmuştur (Little ve Little,2001).

$\mathrm{Bu}$ ülkeleri takriben İtalyada da okul öncesi eğitim kurumlarında öğretmenleri üç senelik periyodlarla aynı öğrenci gruplarıyla çalışmalarını sağlayarak Looping eğitimi ile ilgili ilklerden biri olmuştur. İtalya'daki okul öncesi eğitimde de üç senelik döngüler şeklinde eğitim verilmektedir. İtalya, üç yıllık eğitim döngülerinin, öğrencilerin öğretmenlerini tanıması ve bu sürenin güven, sevgi gibi güçlü duygular oluşturmada etkili olmasından dolayı öğrenciler için dengeli bir eğitim ortamı yarattı̆̆ını öne sürmüştür (Gandini, 2004).

Eğitim ortamlarında Looping tekniği entegre edilirken aynı yaştan öğrencilerin ortak gruplarda yer aldığı sınıflar kullanılması literatürde önemli bir kriter olarak yer almaktadır (Miller, 1991). Bunun nedeni, looping tekniğinin öğretmen, öğrenci ve veli arasındaki uzun süreli bir bağ anlayışını destekliyor olmasından kaynaklanmaktadır; aynı yaştan öğrencilerin bulunduğu sınıflar sayesinde öğrenciler aynı öğretmenle bir yıldan fazla 
eğitim alabilmektedir (Christenson, Palan ve Scullin, 2009). Fakat, farklı yaş gruplarından öğrencilerin de yer aldığ 1 sınıflarda Looping yöntemi kullanılmaktadır, bu durum özellikle Montessori sınıflarında sıkça görülmektedir (Hegde ve Cassidy, 2004).

Peters (2002), çalışmasında bir bilgi sunum yöntemi olarak Looping tekniğinin öğretime etkilerini incelemiştir. Araştırmanın örneklemini iki yüz yetişkin, iki yüz öğrenci ve yirmi üç öğretmen oluşturmaktadır. Katılımcılardan veri toplamak amacıyla test sonuçları, disiplin raporları, ebeveyn-öğrenci anketleri ve öğretmenlerle görüşmeler yapılmıştır. Çalışmanın sonucunda, Looping eğitiminin öğretmenlerin Looping tekniğinin sınıf ortamını geliştirmede olumlu sonuçlar yarattı̆̆ düşüncesini ifade ettikleri belirtilmiş, Looping eğitimi sürecinde öğrencilerin test sonuçları kıyaslandığında da öğrencilerde disiplin problemlerinde düşüş, ders başarısında artış olduğu bulunmuştur.

2001 yılında yapılmış olan bir çalışmada, ilkokul öğretmenlerinin Looping tekniği üzerine görüşleri incelenmiş ve Looping yönteminin Afrika Amerikalı erkeklerin akademik ve sosyal gelişimleri üzerindeki etkisi araştırılmışır. Araştırmanın örneklemini North Carolina'da yirmi yedi adet ilkokulda Looping çalışması yapmış kırk yedi öğretmen oluşturmaktadır. Veri toplama yöntemi olarak otuz soruluk anketler ve dört adet açı uçlu soru kullanılmıştır. Araştırmanın sonucunda, Looping tekniğinin çocuklar üzerinde, özellikle Afro Amerikan erkekler üzerinde olumlu etkisi olduğu ve öğrencilerin etkileşime geçmek ve akademik-sosyal becerilerin gelişiminde etkili olduğu ortaya çıkmıştır (Jordan, 2001).

2004 yılında yapılmış olan bir araştırmaya göre, Looping tekniğinin öğretmen ve veliler arasındaki bağı pekiştirmede etkili olduğu ortaya çıkmıştır (Hegde ve Cassidy,2004). Ayrıca öğrenciler belirli zaman periyodu süresince aynı sınıf arkadaşları ve öğretmeni ile olacağından dolayı, arkadaşlarına karşı güven duyma seviyelerinde artış olduğu, tartışma yürütme ve problem çözme becerilerinde gelişim olduğu da ifade edilmiştir (Lincoln, 1997). Looping tekniği ile eğitim gören öğrencilerde ayrıca bağımsız okuma becerilerinde artış görülmüştür (Roberts, 2003).

Menconi (2006), okul idarecilerinin Looping eğitimine ilişkin algılarını araştırmıştır. Araştırmanın çalışma grubu, üç farklı bölgeden biri Looping eğitimini uygulamakta olan bir okul, biri Looping ve çoklu-yaş eğitimini uygulayan bir okul, biri de şehir merkezinde olan bir okul olmak üzere belirlenmiştir. Araştırmada, okul idarecilerinin Looping eğitimine ilişkin karşılaştıkları bazı zorluklar olduğunu düşündükleri, fakat Looping eğitiminin öğrenci merkezli öğretim sağladığını, farklılaştırılmış eğitimi ve sınıf kademeleri arasında sorunsuz geçişleri sağladığını düşündükleri ortaya çıkmıştır.

2007 yılında yapılmış olan bir çalışmada, Looping eğitimi ile öğretim gören öğrencilerin öğrenci bağl1lı̆̆ seviyeleri ölçülmüştür. Çalışma Amerika Birleşik Devletlerinde iki adet okuldan veli ve öğrencilerin de içinde bulunduğu 41 katılımcının olduğu bir çalışma grubuyla yürütülmüştür. Araştırmanın sonucunda Looping eğitiminin bağlanma seviyelerinde artışa neden olduğu bulunmuştur (Bulau,2007).

Barger (2013), Looping eğitiminin ortaokul fen başarı testlerine etkisini incelemiştir. Çalışma kapsamında, nedensel-karşılaştırılmalı desen kullanılmıştır. Araştırmanın örneklemi, yüz seksen dokuz adet okuldan oluşmaktadır. Örneklem kapsamında, yüz kırk altı adet okulda sekizinci sınıfta Looping eğitimi kullanılmadığı, otuz iki tanesinde ise kullanıldığı belirtilmiştir. Veri toplama aracı olarak, fen bilimlerini ve okuma becerilerini ölçen başarı testleri ve araştırmacının kendi geliştirdiği bir anket kullanılmıştır. Çalışmanın sonucunda, Looping eğitiminin belirli bir zaman çizelgesi oluşturmaya yardım ettiği, öğrenci-öğrenci, öğrenci-öğretmen ilişkilerini güçlendirdiği, öğrenci destekleyici olduğu ortaya çıkmıştır. Bu sonuçlarla ilişkili olarak, Looping eğitiminin bir fen öğretmeninin müfredata uygun biçimde ve ilkokul ya da ortaokul seviyesinde öğrencilerin gelişimsel düzeylerine uygun bir eğitim sunmasını sağladığı ortaya çıkmıştır.

Looping eğitiminde aynı gruba iki veya üç senelik dönemler boyunca aynı sınıf arkadaşları ve öğretmenle eğitim verildiğinden ötürü, bu sistemle eğitim gören öğrencilerin uzun süreli öğrenme becerilerinin geliştiği belirtilmiştir (Minkel, 2015). Ayrıca öğretmenlerin de öğrencilerin öğrenme becerileri ve karakterleri hakkında uzun dönemde bilgi sahibi olduğundan etkili bir farklılaştırılmış eğitim sundukları da belirtilmiştir (Roberts, 2003). Yapılan çalışmalara göre, Looping eğitiminin öğretmenlerin öğrencilerle ve velilerle bağ kurmayı sağladığından ötürü, yakın ilişkiler kurmaya yardımcı olduğu ve dolaylı olarak da öğrenci başarısına olumlu etkisi olduğu ifade edilmiştir.

Yapılan alanyazın taraması sonucunda, ulusal kaynaklarda Looping eğitiminin öğrencilere etkisine ilişkin yeterli çalışma bulunmadığı belirlenmiştir. Alanyazındaki bu eksiklikten dolayı yapılan bu çalışmada, Looping eğitiminin öğrencilere etkisinin incelendiği araştırmalar bir araya getirilmiştir. Araştırmanın sorusu "Looping eğitiminin öğrencilere etkisi ne şekildedir?” olarak belirlenmiştir. Belirtilen problem cümlesine ilişkin beş adet alt problem cümlesi belirlenmiştir. 
1) Looping eğitiminin etkilerine ilişkin yapılmış çalışmaların yapıldığı yıllara göre dağılımı ne şekildedir?

2) Looping eğitiminin etkilerine ilişkin yapılmış çalışmaların kullanılan ölçme metodolojilerine göre dağılımı ne şekildedir?

3) Looping eğitiminin etkilerine ilişkin yapılmış çalışmaların kullanılan ölçme araçlarına göre dağılımı ne şekildedir?

4) Looping eğitiminin etkilerine ilişkin yapılmış çalışmaların okul kademelerine göre dağılımı ne şekildedir?

5) Looping eğitiminin etkilerine ilişkin yapılmış çalışmaların yapıldıkları ülkelere göre dağılımı ne şekildedir?

6) Looping eğitiminin etkilerine ilişkin yapılmış çalışmaların türlerine göre dağılımı ne şekildedir?

\section{Çalışmanın Türü}

\section{Yöntem}

$\mathrm{Bu}$ derleme çalışmasının amacı, Looping sistemiyle verilen eğitimin öğrenciler üzerindeki etkisini incelemek için literatürdeki çalışmaları inceleyerek konuya ilişkin genel bir özet ortaya koymak ve alana ilişkin ulusal kaynaklardaki eksikliği tamamlamaktır.

Bu makalede sistematik derleme türü kullanılmıştır. Sistematik derleme, literatüre ilişkin çalışmaların seçilip eleştirel olarak değerlendirilmesi, bu çalışmalardan veri toplanması ve analiz edilmesini ifade eden bir araştırma yöntemi olarak tanımlanmıștır (Liberati, Altman, Tetzlaff, Mulrow, Gøtzsche, Ionnidis, Clarke, Devereaux, Kleijnen ve Moher, 2009). Sistematik derlemeler, belirli bir konuda yapılmış çalışmaları özetlemek için kullanılan etkili bir çalışma olduğundan dolayı literatüre önemli katkılarda bulunan çalışmalardır (Aaron, 2008).

\section{Veri Toplama}

Çalışma kapsamında, konu üzerine yapılmış ulusal kaynak bulunamadığından uluslararası kaynaklar kullanılmıştır. Derlemeye katılan çalışmalar arasında tezler ve makaleler vardır. Araştırma makalesi olmayan çalıșmalar dâhil edilmemiştir. Çalışma kapsamında Google Scholar, Semantic Scholar, ProQuest ve ERIC veritabanlarında "Looping" ve "Looping Education" anahtar kelimeleri ile tarama yapılmıştır. 2000-2021 yılları arasında yayınlanmış toplam 16 adet çalışma incelenmiştir. Derlenen çalışmalar (a)yayınlanma yılları, (b) kullanılan ölçme metodolojisi, (c) kullanılan ölçme araçları ve (d) çalışmaların yürütüldüğü okul kademesi (e)çalışmanın yürütüldüğü ülke ve (f) çalışmanın türü olmak üzere altı temel alanda incelenmiştir.

Şekil 1. Sistematik Derleme Sürecinin Özeti

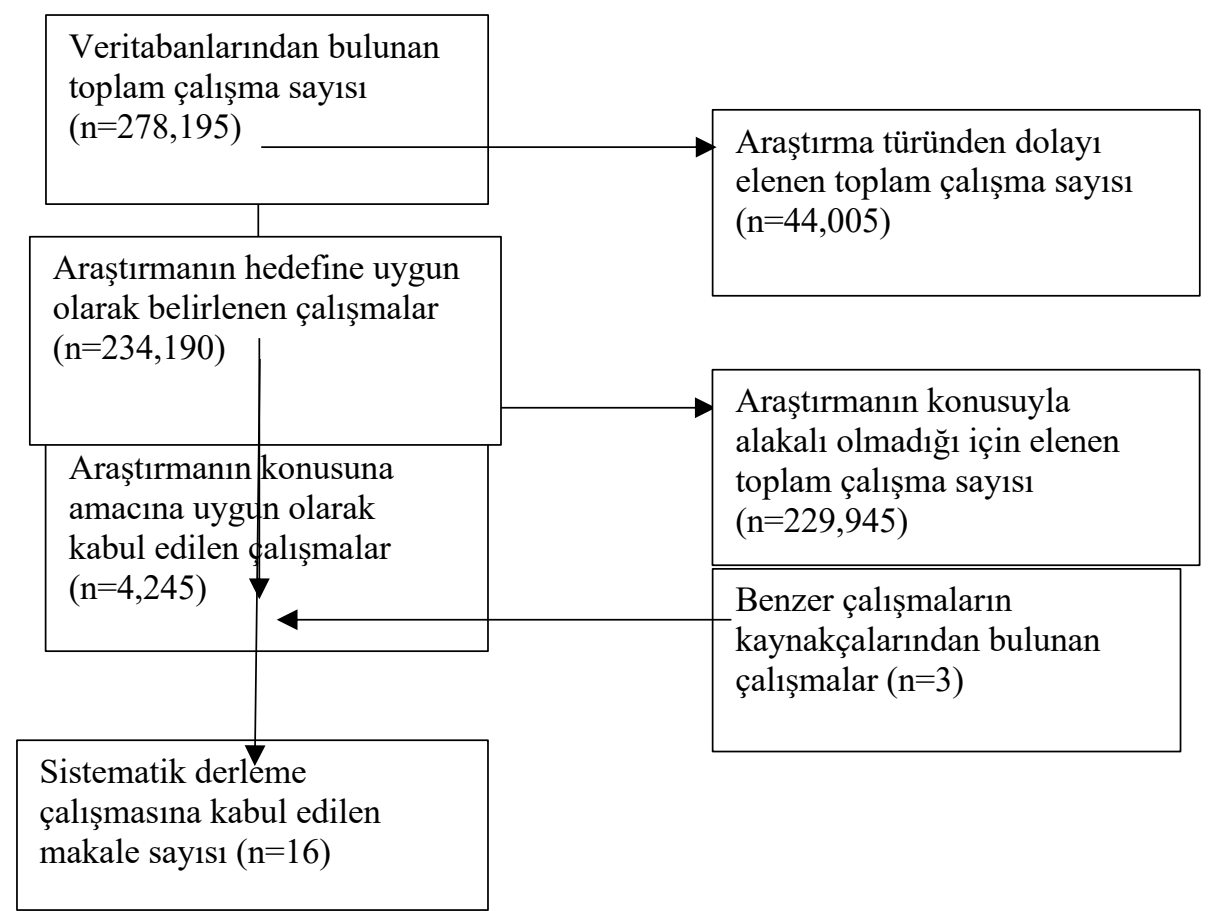




\section{İncelenen Çalışmalar}

\section{Bulgular}

Westerfield, 2009 yılında yaptığı çalışmasında, Looping eğitiminin kırsal kesimde eğitim görmekte olan siyahi ortaokul öğrencilerinin aidiyet hissi üzerindeki etkisini incelemiştir. Çalışmanın örneklemi Mississippi'nin kırsal kesiminde, yedinci sınıf ve sekizinci sınıf kademelerinde öğrenim görmekte olan yedi adet siyahi öğrenciden oluşmaktadır. Çalışmada nicel desen kullanılmış olup, veri toplamak için görüşme, gözlem ve doküman analizi araçlarından yararlanılmıştır. Araştırmanın sonucunda, Looping eğitiminin siyahi öğrencilerin aidiyet hissini artırıcı yöne olduğu ortaya çıkmıştır.

Washington (2015), Looping eğitiminin ikinci, üçüncü, dördüncü ve beşinci sınıf öğrencilerinin okuma becerileri ve matematik seviyelerine ilişkin etkisi araştırılmıştır. Araştırmada nedensel-karşılaştırmalı desen kullanılmış olup, çalışma kapsamında, Amerika Birleşik Devletleri'nde yer alan sekiz okul bölgesinden merkezi ve kırsal bölgedeki okullardan toplam beş bin dört yüz yetmiş adet, ikinci, üçüncü, dördüncü ve beşinci sinıf kademelerinde öğrenim gören öğrenci katılımda bulunmuştur. Veri toplamak amacıyla The Northwest Evaluation Association Measure of Academic Progress ölçeği kullanılmıştır. Çalışmanın sonucunda, Looping eğitiminin öğrencilerin okuma becerilerinde ve matematik seviyelerine olumlu etkisi olduğu ortaya çıkmıştır.

Belcher, 2020 yılında yaptığ çalışmasında, okul öncesi ve ilkokulda Looping eğitimi görn öğrencilerin, üçüncü, dördüncü ve beşinci sınıflarda girdikleri okuma testlerindeki performanslarını ölçmüştür. Çalışmada, nitel araştırma deseni kullanılmış ve veri toplamak için English Language Arts State Assessment testi kullanılmıştır. Araştırmanın örneklemi, üç yüz on beş adet üçüncü sınıf öğrencisi, yüz seksen üç adet dördüncü sınıf öğrencisi ve yüz beş adet beşinci sınıf öğrencisinden oluşmaktadır. Katılımcılardan yüz altmış sekiz adet öğrenci daha önce Looping eğitimi almışlardır. Araştırmanın sonucunda, Looping eğitimi almış olan öğrenciler diğer öğrencilere kıyasla daha yüksek puanlar almışlardır. Sonuç olarak Looping eğitiminin ev-okul bağlantısını güçlendirdiği ortaya çıkmıştır.

Danley (2012), çalışmasıyla, looping eğitiminin şehirde öğretim gören üçüncü sınıf öğrencilerine etkisini incelemiştir. Araştırmanın örneklemini, Amerika Birleşik Devletleri’nin güneydoğusunda yer alan Looping eğitimi veren on altı okul ve daha önce Looping eğitimi almamış olan öğrencilerin olduğu, Looping sınıflarının mevcut olduğu on altı adet okul seçilmiştir. Öğrencilere ek olarak, bu örneklemde bulunan üçüncü sınıf öğrencilerinden Looping eğitimi alanların yüz altı adet ebeveyni ve yine aynı örneklemden Looping eğitimi almayan üçüncü sınıfta eğitim gören çocuğu olan yüz yirmi adet ebeveyn de çalışmada katılım göstermiştir. Çalışmada nicel bir desen kullanılmış olup ölçme aracı olarak başarı testleri ve anket araçları kullanılmıştır. Araştırmanın sonucunda, Looping eğitiminin öğrencilerin eğitimini destekleyici olduğu ifade edilmiştir.

Snoke (2007), Looping eğitim programının Pennysylvania'daki iki adet okuldaki öğrencilerin akademik becerilerine etkisini, bilgilerin kalıcılığını ve özel eğitime ilişkin etkilerini incelemiş̧tir. Çalışmanın deseni nedenselkarşılaştırmalı desen olarak belirtilmiştir. Araştırmanın örneklemini, Looping eğitimi alan ve almayan toplam bin on altı adet üçüncü, dördüncü, beşinci ve sekizinci sınıf öğrencileri oluşturmaktadır. Veri toplamak için Pennysylvania System of School Assessment aracı kullanılmıştır. Çalışmanın sonucunda, Looping eğitiminin özel eğitime olan ihtiyacı azalttığı ifade edilmiştir. Ayrıca, Looping eğitiminin öğrencilerin hazırbulunuşluk düzeylerini etkilediği ve öğrencilerin yeteneklerinin keşfedilmesinde etkili olduğu belirtilmiştir.

Gregory (2009), Looping eğitiminin ortaokul öğrencilerinin akademik ve sosyal tecrübelerine etkisini incelemiştir. Çalışmada nicel desen kullanılmış, araştırmanın örneklemini ise Gürcistan'da bir ilkokuldaki iki yüz kırk adet sekizinci sınıf öğrencisinden oluşmaktadır. Katılımcılar daha sonra her grupta bir adet özel eğitim öğretmeni de dahil olmak üzere sekiz adet çalışma grubuna ayrılmışır. Veri toplama aracı olarak Georgia Criterion Referenced Competencty test ve 8th Grade Writing Assessment başarı testleri ayrıca okul çalışanlarının geliştirdiği bir adet anket kullanılmıştır. Çalışmanın sonucunda, Looping eğitiminin öğrencileri ileriki eğitim kademelerine ilişkin daha rahat hisettirdiği, öğrencilerin sınıf arkadaşları ve öğretmen arasındaki ilişkileri güçlendirdiği ortaya çıkmıştır.

Holmes (2008), Looping eğitiminin yüksek başarı gösteren okullardaki öğrencilerin başarılarına etkisini araştırmıştır. Çalışmada nicel desen kullanılmıştır. Çalışmanın örneklemini daha önce Looping eğitimi almış ve almamış toplam iki yüz yirmi sekiz öğrenci oluşturmaktadır. Veri toplamak için Georgia Criterion Referenced Competency Test ve Cognitive Abilities Test kullanılmıştır. Sonuç olarak, Looping eğitiminin öğrencilerin becerilerini ve zayıf yönlerini öğrenmek ve akademik anlamda gelişmek için yararlı olduğu ortaya çıkmıştır.

Almeida (2004), Looping eğitiminin dördüncü sınıf öğrencilerinin okuma başarılarına etkisini incelemiştir. Çalışmada nedensel-karşılaştırmalı desen tercih edilmiş olup örneklem seksen bir adet dördüncü sınıf öğrencisinden oluşmaktadır. Veri toplamak için Metropolitan Achievement Test, Florida Comprehensive Achievement Test ve StateTrait Anxiety Inventory for Children araçları kullanılmıştır. Araştırmanın sonucunda, daha önce Looping sistemiyle eğitim görmüş olan öğrencilerin okuma başarılarının diğer öğrencilere göre daha yüksek olduğu bulunmuştur. 
2017 yılında yapılmış olan bir çalışmada, Looping sisteminin Çin'deki öğrencilerin başarısına etkisi incelenmiştir. Nicel desenin kullanıldığı bu çalışma kapsamında, toplam altmış iki okuldaki öğretmen ve öğrenciler katılımcı olmuşlardır. Veri toplama aracı olarak anket kullanılmıştır. Araştırmanın sonucunda Looping sisteminin, ekonomik düzeyi düşük olan öğrencilerin başarısını artırmada etkili olduğu ortaya çıkmıştır (Wang, Wu, Shi, Chen, Loyalka, Chu, Kenny ve Rozelle, 2017).

Bulau (2007), Looping sisteminin öğrenci bağlanmasına etkisini araştırmıştır. Bu çalışmada nitel desen kullanılmıştır. Çalışmanın örneklemini, Amerika Birleşik Devletleri’nin güneydoğusunda yer alan iki ilkokulun öğrencileri oluşturmaktadır. Çalışma kapsamında veri toplamak için, anket ve görüşme yöntemleri kullanılmıştır. Kırk bir katılımcı anketi doldurmuş, yirmi katılımcı yüzyüze görüşmede bulunmuştur. Çalışma sonucunda Looping sisteminin okulu öğrenciler için daha samimi ve güvenilir haline getirdiği ifade edilmiştir.

Sherman (2000), ortaokul öğrencilerinde Looping eğitiminin sınav sonuçlarına etkisini ölçmüştür. Araştırmanın örneklemini Midwestern Ortaokulundaki yüz yetmiş sekiz tane sekizinci sınıf öğrencisinden oluşmaktadır. Veri toplamak için Iowa Test of Basic Skills (ITBS) ve Iowa Test of Educational Development (ITED) testleri kullanılmışır. Araştırmanın sonucunda, Looping tekniği kullanılan gruptaki kız öğrencilerin akademik başarısının, sıradan eğitim yöntemleriyle öğretim gören sınıftaki öğrencilere göre daha yüksek olduğu ortaya çıkmıştır.

O’Neill, 2002 yılında yapmış olduğu çalışmada, Looping eğitiminin ilkokul öğrencilerinin başarısı üzerindeki etkisini araştırmıştır. İkisi de ilkokul seviyesinde olan Looping eğitimi alan bir sınıfı ve normal eğitim yöntemlerinin uygulandığı iki sınıftan da test yöntemiyle veri toplanmıştır. Çalışma kapsamında öğrenciler test sonuçları, sosyoekonomik düzey ve öğretmen tecrübesi gibi gruplara ayrılmışlardır. Araştırmanın sonucunda Looping tekniğinin okuma becerileri ve matematik eğitimi üzerinde olumlu etkileri olduğu bulunmuştur.

Tucker (2006), Looping sisteminde verilen eğitimin Colorado Başarı Programı'na göre öğrenci başarısı üzerine etkisini araştırmışırı. Nedensel-karşılaştırmalı desenin kullanıldığı çalışma kapsamında yedinci sınıf kademesinde bulunan, Looping sisteminde eğitim almış ve geleneksel eğitim sisteminde öğretim görmüş olan iki yüz on yedi öğrenci katılımda bulunmuştur. Veri toplamak için Colorado Student Assessment Program test kullanılmıştır. Çalışma sonucunda, Looping sisteminde eğitim almış olan ve geleneksel eğitim sisteminde öğretim görmüş öğrenciler arasında matematik bilgisi alanında büyük farklılıklar göze çarpmıştır. Looping sisteminde eğitim almış olan öğrenciler matematik alanında daha başarılı sonuçlar elde etmiştir.

Riley (2014), Looping sisteminde verilen eğitimin ikinci sınıf öğrencilerinin okuma başarılarına ve okula yönelik tutumlarına ilişkin etkisini ölçmüştür. Çalışmada yarı-deneysel bir desen kullanılmış olup, hepsi ikinci sınıf kademesinde olan toplam yirmi sekiz adet, bir sene Looping öğretimi görmüş olan on dört adet öğrenci ve Looping sistemiyle öğretim görmemiş on dört adet öğrenci katılımc1 olarak belirlenmiştir. Veri toplamak için The Fountas \& Pinnell Benchmark Assessment System başarı testi ve araştırmacının kendisi geliştirmiş olduğu bir anket kullanılmıştır. Çalışmanın sonucunda, Looping sistemiyle öğretim görmüş olan öğrencilerin okulda kendini rahat hissettikleri ve okuma becerilerinin daha yüksek olduğu ortaya çıkmıştır.

2004 yılında yapılmış olan bir çalışmada, Looping eğitiminin dördüncü sınıf öğrencilerinin okuma başarıları üzerindeki etkisi araştırılmıştır. Çalışmanın örneklemi, seksen bir adet dördüncü sınıf öğrencisinden oluşmaktadır ve veri toplamak için belirlenen çalışma gruplarına Metropolitan Achievement Test- Seventh Edition ölçeği uygulanmış ve doküman inceleme yaparak öğrencilerin okuma becerilerine ilişkin ders notları incelenmiştir. Araştırmanın sonucunda Looping eğitiminin öğrencilerin okuma becerilerinde önemli miktarda gelişme sağladığı ortaya çıkmıştır (Almeida, 2004).

Gilliam (2005), Looping eğitiminin ortaokul öğrencilerinin öğretimine etkisini incelemiştir. Araştırmada iki şehir okulunda görev yapmakta olan on bir adet öğretmen yer almıştır. Veri toplamak için anket, diyalog, görüşme ve gözlem yöntemleri kullanılmıştır. Araştırmanın sonucuna göre, Looping eğitiminin öğrencilerin akademik başarısında olumlu bir etkisi olduğu belirlenmiştir.

\section{Araştırma Sorularına İlişkin Bulgular}

Tablo 1: Çalışmaların Yıllara Göre Dağılımı

\begin{tabular}{lllllllllllllll}
\hline Y1llar & 2000 & 2002 & 2004 & 2005 & 2006 & 2007 & 2008 & 2009 & 2012 & 2013 & 2014 & 2015 & 2017 & 2020 \\
\hline $\mathrm{f}$ & 1 & 1 & 1 & 1 & 1 & 2 & 1 & 2 & 1 & 1 & 1 & 1 & 1 & 1 \\
$\%$ & 6.25 & 6.25 & 6.25 & 6.25 & 6.25 & 12.5 & 6.25 & 12.5 & 6.25 & 6.25 & 6.25 & 6.25 & 6.25 & 6.25 \\
\hline
\end{tabular}


Çalışmalar yapılma yıllarına göre incelendiklerinde, Looping eğitiminin etkilerine ilişkin en fazla sayıda çalışmanın 2007 (\%12.5) ve 2009 (\%12.5) yıllarında yapılmış olduğu ortaya çıkmıştır.

Tablo 2: Çalışmaların Ölçme Metodolojilerine Göre Dağılımı

\begin{tabular}{lllll}
\hline Ölçme metodolojisi & Nitel & Nicel & Yarı-Deneysel & Nedensel-Karşılaş̧ırmalı \\
\hline $\mathrm{f}$ & 2 & 7 & 2 & 5 \\
$\%$ & 12.5 & 43.75 & 12.5 & 31.25 \\
\hline
\end{tabular}

Yapılan çalışmalar, kullanılan ölçme metodolojilerine göre sınıflandırıldıklarında en çok kullanılan desenin nicel desen $(\% 43.75)$ olduğu ortaya çıkmıştır.

Tablo 3: Çalışmaların Kullanılan Ölçme Araçlarına Göre Dă̆glımı

\begin{tabular}{|c|c|c|c|c|c|c|c|c|}
\hline $\begin{array}{l}\text { Ölçme } \\
\text { araçları }\end{array}$ & Anket & $\begin{array}{l}\text { Başarı } \\
\text { testi }\end{array}$ & $\begin{array}{l}\text { Doküman } \\
\text { inceleme }\end{array}$ & $\begin{array}{l}\text { Başarı testi } \\
\text { ve döküman } \\
\text { inceleme }\end{array}$ & $\begin{array}{l}\text { Görüşme } \\
\text { ve gözlem }\end{array}$ & $\begin{array}{l}\text { Anket ve } \\
\text { başarı } \\
\text { testi }\end{array}$ & $\begin{array}{l}\text { Anket ve } \\
\text { görüşme }\end{array}$ & $\begin{array}{l}\text { Görüşme, } \\
\text { gözlem ve } \\
\text { doküman } \\
\text { analizi }\end{array}$ \\
\hline$f$ & 1 & 7 & 1 & 1 & 1 & 3 & 1 & 1 \\
\hline$\%$ & 6.25 & 43.75 & 6.25 & 6.25 & 6.25 & 18.75 & 6.25 & 6.25 \\
\hline
\end{tabular}

Yapılan çalışmalar veri toplamak için kullanılan ölçme araçlarına göre incelendiğinde, en çok kullanılan ölçme aracı başarı testleri (\%47.05) olarak ortaya çıkmıştır. Ardından anket ve başarı testlerinin (\%17.6) kullanıldığı belirlenmiştir.

Tablo 4: Çalışmaların Yürütüldüğü Okul Kademesine Göre Dağılımı

\begin{tabular}{|c|c|c|}
\hline Sinif & $\mathrm{f}$ & $\%$ \\
\hline 2.sinif & 1 & 6.25 \\
\hline 3.sinif & 1 & 6.25 \\
\hline 4.sinif & 1 & 6.25 \\
\hline 7.sinif & 1 & 6.25 \\
\hline 8.sinif & 2 & 12.5 \\
\hline 1 ve $4 . \sin 1 f$ & 1 & 6.25 \\
\hline $1,2,3,4,5$ ve $6 . \sin 1 f$ & 1 & 6.25 \\
\hline 3,4 ve $5 . \sin 1 f$ & 1 & 6.25 \\
\hline 3,5 ve8.sinif & 1 & 6.25 \\
\hline 2,4 ve $6 . \sin 1 f$ & 1 & 6.25 \\
\hline $2,3,4$ ve 5. sinif & 2 & 12.5 \\
\hline 7. ve $8 . \sin 1 f$ & 1 & 6.25 \\
\hline 6,7 ve $8 . \sin 1 f$ & 1 & 6.25 \\
\hline 4,8 ve $11 . \sin 1 f$ & 1 & 6.25 \\
\hline
\end{tabular}

Literatüre ilişkin yapılmış çalışmaların çeşitli kademelerde öğrenim gören öğrencilerin dağılımına göre incelendiğinde, en fazla çalışmanın 8 .sınıf öğrencileri ve 2,3,4 ve 5.sınıf öğrencileriyle yapılmış olduğu ortaya çıkmıştır. 
Tablo 5: Çalışmaların Yapıldıkları Ülkelere Göre Dă̆ı̆ımı

\begin{tabular}{lll}
\hline Ülkeler & ABD & Çin \\
\hline $\mathrm{F}$ & 15 & 1 \\
$\%$ & 93.75 & 6.25 \\
\hline
\end{tabular}

Alanda yapılmış olan çalışmalar, yürütüldükleri ülkelere göre sınıflandırıldıklarında, konuya ilişkin en çok çalışmanın Amerika Birleşik Devletleri'nde yapıldığı ortaya çıkmıştır.

Tablo 6: Çalışmaların Türüne Göre ağılımı

\begin{tabular}{lll}
\hline Çalışmanın türü & Tez & Makale \\
\hline $\mathrm{F}$ & 15 & 1 \\
$\%$ & 93.75 & 6.25 \\
\hline
\end{tabular}

Alana ilişkin yapılmış çalışmalar türlerine göre sınıflandırıldıklarında en çok çalışmanın tez türünde yapılmış olduğu ortaya çıkmıştır.

\section{Sonuç}

Looping yöntemi, bir öğretmenin aynı öğrencileriyle iki veya daha fazla öğretim yılı boyunca eğitime devam etmesini içeren bir eğitim tekniği olarak ifade edilmiştir (Leckrone ve Griffith, 2006). Yapılan çalışmalarda Looping öğretiminin, öğretmenlerin öğrencileriyle bağ kurarak eğitsel ihtiyaçlarını daha iyi belirleyebildiklerini ve bu eğitsel ihtiyaçları daha kolay karşılayabildiklerini belirtilmiştir (Snyder, 2003). Dolayısıyla Looping eğitimine ilişkin çalışmalar yapılması, öğrencilerin eğitim ihtiyaçlarını tanımlamak ve eğitsel ihtiyaçların anlaşılması için önem taşımaktadır. Bu sistematik derleme çalışmasında, Looping öğretiminin öğrencilere etkisini inceleyen araştırmalar incelenmiştir. Taranan makaleler 2000-2020 yılları arasında yayınlanmış olan tezlerden ve makalelerden oluşmaktadır. $\mathrm{Bu}$ çalışma ile daha önce yapılmış çalışmalar bir araya getirilerek ulusal literatürdeki eksikliğin doldurulması amaçlanmiştır.

Çalışma kapsamında makaleler yayınlanma yıllarına, kullanılan ölçme metodolojisine, kullanılan ölçme araçlarına, çalışmaların yürütüldügü okul kademesine, çalışmaların yürütüldüğü ülkelere ve çalışmanın türüne olmak üzere altı tana başlık altında incelenmiştir. Literatüre ilişkin çalışmalar yayınlanma yıllarına göre ele alındığında, 2007 ve 2009 yıllarında yapılmış olan çalışmalar ağırlıkta görünmektedir. Taranan çalışmalarda en fazla kullanılan ölçme metodolojisinin nicel desen $(\% 43.75)$ olduğu ortaya çıkmıştır. Çalışmalarda en çok kullanılan ölçme aracının başarı testleri (\%43.75) olduğu görülmüştür. Literatüre ilişkin araştırmaların en çok 8.sınıf ve 2, 3, 4 ve 5.sınıf öğrencileriyle yapıldığ1 ortaya çıkmıştır. Derlenen çalışmalar türleri bakımından sınıflandırıldıklarında, alana ilişkin tez çalışmalarının ağırlıkta olduğu bulunmuştur. İlgili konuda çalışma yapan ülkeler Amerika Birleşik Devletleri (ABD) ve Çin Halk Cumhuriyeti olduğu görülmüştür ve en çok çalışma yapan ülke ABD olarak belirlenmiştir.

Literatür taraması sonucunda, Looping eğitiminin öğrenci, öğretmen ve okul başarısı başta olmak üzere birçok yararı olduğu ortaya çıkmıştır. Looping tekniğinin, öğrencilerin okula aidiyet hissiyatı geliştirmesine yardımcı olduğu, bireylerin okulda kendilerini daha rahat hissetmesine yardımcı olduğu, öğrencilerin arkadaşları ve öğretmenleriyle ilişkini güçlendirici olduğu ve ev-okul bağlantısını güçlendirdiği ortaya çıkmıştır.

Bunun yanı sıra Looping eğitiminin öğrencilerin akademik gelişimine bazı etkileri olduğu da belirlenmiştir. Looping'in öğrencilerin okuma becerilerine ve matematik seviyelerine olumlu etkisi olduğu, öğrencilerin okuma becerilerini artırdığı yönde ve öğrencilerin hazırbulunuşluk düzeylerinde etkili olduğu gözlemlenmiştir. Kısacası, öğrencilerin becerilerini geliştirici etkisiyle birlikte bireylerin zayıf yönlerini öğrenmelerini de sağlayarak akademik anlamda öğrencileri geliştirmede ve eğitimlerini destekleyici şekilde yararlı olduğu ortaya çıkmıştır.

$\mathrm{Bu}$ çalışma kapsamında Google Scholar, Semantic Scholar, ProQuest ve ERIC veritabanlarında tarama yapılmış ve 2000-2020 yılları arasında yayınlanmış olan makale ve tezler çalışmaya dâhil edilmiştir. Looping yönteminin etkileri göz önünde bulundurulduğunda alana ilişkin çalışmalarda bu bilgilerden yararlanılmasının uygun olacağı düşünülmektedir.

\section{Araştırmacıların Katkı Oranı}

Yazar çalışmanın tamamını gerçekleştirmiştir.

\section{Destek ve Teşekkür}

Yazar çalışma için herhangi bir finansal destek almamıştır. 
Girgin

Çıkar Çatışması

Yazar çalışmada herhangi bir çıkar çatışmasının bulunmadığını beyan etmiştir. 


\section{Kaynakça / References}

Aaron, L. (2008). Writing a Literature Review Article, Radiologic Technology, 80(2),185-186.

Almeida, M. J. (2004). The impact of looping fourth grade students on their reading achievement. Florida International University, Florida.

Barger, T. M. (2013). Impact of Looping on Middle School Science Standardized Achievement Tests, Liberty University.

Belcher, A. R. (2020). Effects of Looping, Kindergarten to First Grade and Performance on State Reading Tests in Third, Fourht and Fifth Grades: A Case Study, The University of Findlay's College of Education.

Bolaños, J. D. (2012). Educación rural en escuelas primarias de Cuba, Sinéctica, (38), 1-18.

Bulau, R. J. (2007). Looping and its impact on student connectedness. Walden University, Minnesota.

Christenson, C., Palan, R. ve Scullin, S. (2009). Family-school partnerships: An essential component of student achievement. Principal Leadership, 9(9), 10-16.

Danley, A. J. (2012). The Effects of a Looping Classroom Among Third Grade Students in an Urban School District, (Unpublished doctoral dissertation). University of Missouri-Kansas City, USA.

Gandini, L. (2004). Foundations of the Reggio Emilia approach. In J. Hendrick (Ed.), Next steps toward teaching the Reggio way: Accepting the challenge to change. Upper Saddle River, NJ: Pearson Education.

Gaustad, J.(1998). Implementing Looping, Eric Digest,123(98).

Gilliam, L. E. (2005). Good teachers don't let go: A case study of middle school looping teachers. Capella University, Minnesota.

Grant, J., Johnson, B., Richardson, I. 1996). The Looping Handbook: Teachers and Students Progressing Together, England:Crystal Springs Books.

Gregory, B. S. (2009). The impact of looping on academic and social experiences of middle school students, Walden University.

Hegde, A.V. ve Cassidy, D.J. (2004). Teacher and parent perspectives on looping. Early Childhood Education Journa,l 32 (2). 133-138.

Hitz, M.M., Somers, M. ve Jenlink, C. L. (2007). The Looping Classroom: Benefits for Children, Families, and Teachers, Young Children, 62(2), 80-82.

Holmes, N.H. (2008). The impact of looping on student achievement in high performing schools, Walden University.

Johnston, R. C. (2003). A revolutionary education. Education Week. 22(25), 34-41.

Jordan, S. A. (2001). Teachers' perceptions of looping in elementary schools in relation to select demographic variables. The University of North Carolina at Chapel Hill, North Carolina.

Leckrone, M. J. ve Griffith, B. G. (2006). Retention realities and educational standards. Children \& Schools, $28(1), 53$.

Lenart, C. M. (2000). Waldorf schools: Educating the whole child. Conscious Choice.

LeTendre, G. K. (2000). Learning to be adolescent: Growing up in U.S. and Japanese middle schools. New Haven: Yale University Press.

Liberati, A., Altman, D.G., Tetzlaff, J., Mulrow, C., Gøtzsche, P.C:, Ionnidis, J.P.A.,Clarke, M., Devereaux, P.J., Kleijnen, J. ve Moher, D.(2009). The PRISMA statement for systematic reviews and meta-analyses of studies that evaluate health care interventions:explanation and elaboration, Journal of Clinical Epidemology, 62(10).

Lincoln, R. (1997). Multi-year instruction: Establishing student-teacher relationships, Schools In the Middle, 6(3), 50-52.

Little, T. S. ve Little, L. P. (2001). Looping: Creating elementary school communities. Phi Delta Kappa Fastbacks. (478), 7-39 
Girgin

Liu, J. (1997). The Emotional Bond Between Teacher and Students:Multi-year Relationships. Phi Delta Kappan, 79(2), $156-157$.

Mecham, N. A. (2010). A Place to Grow, Young Children, 65(6), 38-40.

Menconi, J. P. (2006). A case study: Principal perspectives of the strengths and weaknesses of looping and multiage education. Loyola University, Chicago, Illinois.

Miller, B. (1991). A review of the qualitative research on multiage instruction, Journal of Research in Rural Education, 7(2), 312.

Minkel, J. (2015). Why Looping Is a Way Underappreciated School-Improvement Initiative. EducationWeek

Morrill, R. (2003). Denmark: Lessons for American principals and teachers? Phi Delta Kappan, 84(6), 460- 463.

O’Neill, K. R. (2002). Looping: A study of multi-year instruction in the primary grades. Eastern Michigan University, Michigan

Peters, B. A. (2002). A case study investigating the perceived benefits and problems of looping at Winchester Elementary School. State University of New York at Buffalo.

Riley, J.(2014). The Effects of Looping on Second Graders' Reading Achievement and Attitudes Towards School, Goucher College.

Roberts, J. M. (2003). A comparative study of student performance in elementary looping and conventional classrooms in selected northern California schools. University of La Verne, California

Roberts, C. (2001). Teachers - and Students - Love to Loop, Edutopia.

Sato, N.(1993). Teaching and learning in Japanese elementary schools: A context for understanding, Peabody Journal of Education,. 68(4),111-149.

Sherman, S. R. (2000). The effect of looping on ITBS and ITED test scores in a midwestern district middle school. Saint Louis University, Missouri.

Snyder, L. L. (2003). An investigation of elementary looping practices and outcomes in a rural school district. The University of Minnesota.

Simel, D. (1998). Education for Bildung:Teacher Attitudes Towards Looping, International Journal of Educational Reform, 7(4),330-337.

Snoke, J. (2007). Looping:the Impact of a Multi-Year Program on the Academic Progress, Retention and Special Education Placements of Students in Two South Central Pennysylvania Schools, Duquesne University.

Tucker, S. C.(2006).The Impact of Looping On Student Achievement On the Colorado Student Assessment Program, Regis University.

Wang, L., Wu, M., Shi, Y., Chen, Y., Loyalka, P., Chu, J., Kenny, K ve Rozelle, S.(2017). The Effect of Teacher Looping on Students Achievement: Evidence from Rural China.

Washington, A.(2015). The Effect of Looping on the Reading and Math Grade Equivalencies of Second, Third, Fourth and Fifth Grade Students, Tennessee State University.

Westerfield, T.S.(2009). The Effect of Looping and Teaming on Rural Black Middle School Students' Sense of Belonging, Mississippi State University. 